\title{
Mechanism of soil stratum instability induced by hydrate dissociation
}

\author{
X.H. Zhang ${ }^{\mathrm{a}, *}$, X.B. Lu ${ }^{\mathrm{a}}$, X.D. Chen ${ }^{\mathrm{a}}$, L.M. Zhang ${ }^{\mathrm{b}}$, Y.H. Shi ${ }^{\mathrm{c}}$ \\ a Institute of Mechanics, Chinese Academy of Sciences, Beijing, China \\ ${ }^{\mathrm{b}}$ Hong Kong University of Science and Technology, Clear Water Bay, Hong Kong \\ c Guangzhou Marine Geological Survey Guangzhou, 510075, China
}

\section{A R T I C L E I N F O}

\section{Article history:}

Received 14 January 2016

Received in revised form

22 April 2016

Accepted 10 June 2016

Available online 25 June 2016

Keywords:

Hydrate dissociation

Centrifugal test

Heat transfer

Slope stability

Fractures

\begin{abstract}
A B S T R A C T
Gas hydrate dissociation may lead to soil stratum instability such as marine landslides in hydrate-bearing sediments. In this paper, centrifugal tests were conducted to investigate the soil responses and stratum instability of a $14^{\circ}$ slope during hydrate dissociation under centrifugal accelerations of $50 \mathrm{~g}$ and $100 \mathrm{~g}$, different boundary conditions and heating modes. New phenomena such as sliding of the over layer, layered fractures between the hydrate layer and the over layer, and fractures in the over layer were observed. The fluid pressures, horizontal displacements and vertical displacements of the soils were measured and compared under different conditions. The observed mechanisms and decoupled formulations considering heat transfer, fluid seepage, soil deformation and critical soil failure were presented and discussed. The formation of layered fractures during hydrate dissociation is regarded as an important factor leading to the instability of the slope.
\end{abstract}

(c) 2016 Elsevier Ltd. All rights reserved.

\section{Introduction}

Thermal disturbances to a hydrate stratum during hydrate exploitation or natural environmental changes may cause the dissociation of hydrate, releasing 164 times of gas in volume and 0.8 times of water into the pore space (Xu and Germanovich, 2006). The expansion of the hydrate dissociation zone will greatly reduce the stiffness and strength of the hydrate-bearing sediment (HBS) (Lu et al., 2008a, 2008b; Song et al., 2014; Jiang et al., 2014; Hyodo et al., 2014; Zhang et al., 2015a). Excess pore fluid pressure develops in a low permeability hydrate stratum. The soil responses during hydrate dissociation may lead to geological and engineering hazards such as marine landslides, seabed subsidence, destruction of oil pipes and gas blowouts (Sultan et al., 2004; Xu and Germanovich, 2006; Kwon et al., 2008; Kwon and Cho, 2012; Lu et al., 2013; Zhang et al., 2014).

The marine landslides caused by hydrate dissociation are associated with small slope gradients. The complex processes such as coupled physical and chemical interactions, phase transformation, soil softening and high excess pore pressures involved in the marine slides make such slides much different from conventional landslides (Kimoto et al., 2010; Klar et al., 2010; Kwon and Cho, 2012). The mechanisms of hydrate dissociation-induced marine landslides have not been fully understood.

\footnotetext{
* Corresponding author.

E-mail addresses: zhangxuhui@imech.ac.cn (X.H. Zhang), cezhangl@ust.hk (L.M. Zhang), yaohongshi@126.com (Y.H. Shi).
}

Limit equilibrium methods considering excess pore fluid pressure were presented to investigate the instability of marine slopes (Kayen and Lee, 1991; Borja et al., 2012), but the evolution of the soil failure mechanisms were not considered. Briaud and Chaouch (1997) presented possible tensile failure mechanisms such as hydraulic fracturing and cavity expansion during hydrate dissociation. Zhang et al. (2011) observed layered fractures and gas outburst in the experimental simulation of thermal-induced hydrate dissociation in a Perspex glass cylinder. Layered fractures also occurred during hydrate dissociation in a one dimensional geotechnical centrifugal test, and changes in temperature, pressure and deformation in HBS were obtained (Kwon et al., 2013).

The physical mechanisms of soil stratum instability induced by hydrate dissociation are still not well understood. The time and space relationships between small and large scale soil failures and the damage degree should be made clearer for the evaluation of engineering system safety. Especially, it is necessary to validate the gravitational effects and the mechanism of stratum instabilities at engineering scales. Hence, large scale physical modeling is required to obtain insight into the failure evolution and physical mechanisms during and after hydrate dissociation.

In geotechnical engineering, centrifugal testing is an effective tool to reproduce the gravitational effect and obtain the failure behavior of a large scale soil slope. Based on scaling laws, the modeling concerns with replicating an event comparable to what might exist in the prototype and the results can be extrapolated to a prototype situation (Taylor, 1995). Hence, centrifugal testing is a good choice for simulating the evolution of stratum instabilities 
such as large scale slides during thermal induced hydrate dissociation.

Zhang et al. (2015b) conducted a centrifuge experiment considering the evolution of the hydrate dissociation scales around a heating rod and the effect on the stratum instability. The results showed that large pore pressures and large displacements developed and layered fractures occurred during hydrate dissociation. These phenomena trigger new concerns on what will happen at different hydrate dissociation rates and different boundary constraints to the soil layers, considering the practical environmental conditions. Further centrifuge tests are needed to understand the physical mechanisms of soil instabilities during dissociation.

According to geological surveys and drilling in South China Sea, typical hydrate strata are located from $10 \mathrm{~m}$ to $300 \mathrm{~m}$ below the seabed at a water depth of about $1000 \mathrm{~m}$; the slopes of the soil layers are in the range of $3-15^{\circ}$. This paper aims at investigating the physical mechanisms of soil stratum instabilities during thermal induced hydrate dissociation by geotechnical centrifugal tests, referring the geological and geotechnical conditions in the hydrate zone in South China Sea. In Section 2, details of the geotechnical centrifugal tests are presented, such as the preparation of soil layers, heating modes and boundary constraints. In Section 3, the test results and observations on physical mechanisms are reported, such as pore fluid pressures and vertical and horizontal displacements. In Section 4, the decoupled mathematical formations for heat transfer, seepage and consolidation, and critical condition of soil failures during hydrate dissociation are presented and discussed.

\section{Description of the geotechnical centrifugal tests}

\subsection{Scaling laws}

The basic principle of centrifuge modeling is as follows: if an acceleration of $N$ times gravity $g$ is applied to a material with density $\rho$, then the vertical stress at depth $l_{m}$ in the model (indicated by subscript $m$ ) is given by $\sigma_{m}=\rho N g l_{m}$, and the prototype (indicated by subscript $p$ ) stress is $\sigma_{p}=\rho g l_{p}$. Thus to produce identical stress conditions in the model, i.e., $\rho N g l_{m}=\rho g l_{p}$, the model dimensions must be scaled at $l_{p}=N l_{m}$.

Zhang et al. (2015b) presented the scaling laws for centrifugal testing of stratum failures induced by hydrate dissociation. The characteristic times for four physical processes during hydrate dissociation, which are heat transfer, phase transformation, fluid seepage, and soil deformation, differ by two orders of magnitude. Hence the four processes can be decoupled (Tan, 2011). Accordingly, the soil behavior and failure during hydrate dissociation can be analyzed as follows. First, the heat induced temperature difference $T_{H}-T_{0}$ leads to the hydrate dissociation and expansion in HBS with a hydrate saturation of $S_{h}$. The heating modes determine the length $l$ and fluid pressure $p$ in the dissociation zone based on the heat transfer involving phase transformations. Second, the seepage and consolidation of HBS occur under the effects of selfweight. Finally, the soil layer fails once the critical condition of instability is satisfied. The heating modes affect the expanding speed and length of hydrate dissociation, and the boundary constraints affect the deforming speed and failure degree of the soil layers. Here, the heating modes and boundary constraints are considered to be two controlling factors.

\subsection{The centrifuge and model specimen preparation}

The geotechnical centrifuge at Tsinghua University was used in the tests. The rotational radius of the centrifuge was $2.0 \mathrm{~m}$, and the maximum centrifugal acceleration was $250 \mathrm{~g}$ (Zhang et al., 2015b).

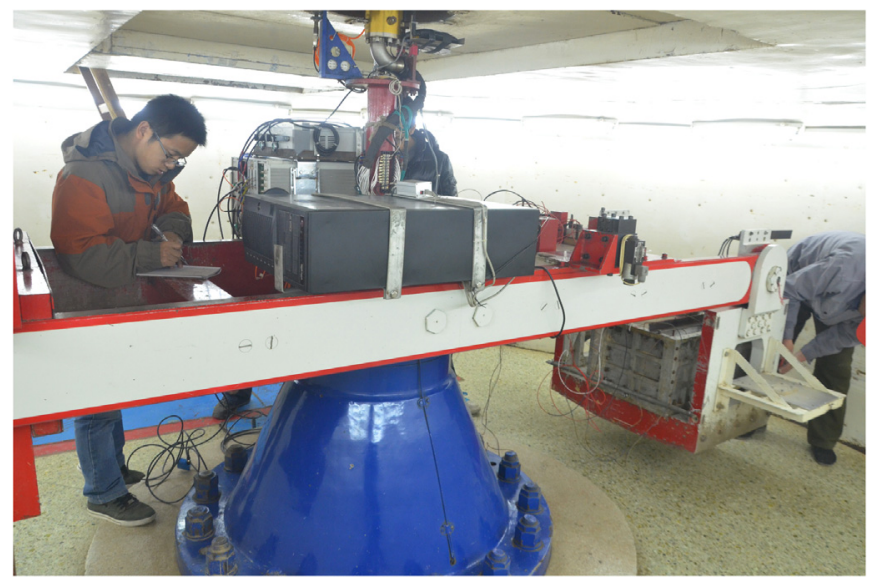

Fig. 1. The centrifuge and the model box.

The dimensions of the model box for the centrifugal tests were $0.6 \mathrm{~m}$ in length, $0.35 \mathrm{~m}$ in width, and $0.4 \mathrm{~m}$ in height (i.e., $60 \mathrm{~m}$ in length, $35 \mathrm{~m}$ in width, and $40 \mathrm{~m}$ in height in prototype scale at an acceleration of $100 \mathrm{~g}$ ). The total weight of the model was about $120 \mathrm{~kg}$ in each test. Fig. 1 shows a photo of the centrifuge and the model box.

The clay in the tests was obtained by drilling in the China Dongsha hydrate area in South China Sea, and the soil layers were prepared according to the in-situ conditions. The slope of the hydrate stratum in South China Sea is about $3-15^{\circ}$, with the typical slope being $14^{\circ}$ based on results of drilling and testing with a gas hydrate-related bottom simulating reflector in 2013 (Sha et al., 2015a, 2015b).

Two layers, the hydrate layer and the over layer were set in the model at a slope of $14^{\circ}$. The dry density of the hydrate layer before hydrate formation was $1.1 \mathrm{~g} / \mathrm{cm}^{3}$ and the porosity was $60 \%$. Tetrahydro-furan (THF) hydrate sediment was synthesized because it is similar to HBS in mechanical and thermal properties and can be prepared uniformly (Yun et al., 2007). The preparation of the hydrate layer was as follows. Firstly, the clay was mixed with the THF solution. In the solution, the water volumetric fraction was $92 \%$ to keep the THF hydrate saturation at $40 \%$ after formation. Secondly, the model box was placed at a slope of $14^{\circ}$, and filled with the test clay, keeping the dry density at $1.1 \mathrm{~g} / \mathrm{cm}^{3}$. Finally, the model box was placed in the refrigerator for about two days with its temperature set at $2{ }^{\circ} \mathrm{C}$ until the THF hydrate formed.

The over layer was prepared after the formation of the hydrate layer, and the density of the layer was set at $1.3 \mathrm{~g} / \mathrm{cm}^{3}$, and the porosity was $52 \%$. The clay was drilled and sampled from the seabed over the hydrate layer. The cohesions of the over layer and the hydrate dissociation layer were $35 \mathrm{kPa}$ and $7 \mathrm{kPa}$, respectively, and the stress path can be referred to Zhang et al. (2015b).

\subsection{Test setups}

The geotechnical response of the soil layers and the mechanism of soil stratum instabilities are concerned during thermal injection exploitation of hydrate in the hydrate layer or exploitation of hot gas underlying the hydrate layer in South China Sea. Table 1 shows the details of six centrifugal tests. Different centrifugal accelerations ( $50 \mathrm{~g}$ and $100 \mathrm{~g}$ ) were adopted to simulate the effect of the absolute thicknesses of soil layers, and the geometrical scale effect was concerned. Heating mode HM1 was adopted to simulate the natural heating of the over layer above the hydrate layer owing to the rising temperature of the seawater. Heating modes HM1, HM2, HM3 and HM4 were used to investigate the effect of the hydrate exploitation modes (i.e. multi-wells, two wells and one well) and 
Table 1

Parameters in each centrifugal test.

\begin{tabular}{|c|c|c|c|c|c|c|c|}
\hline Cases & $\begin{array}{l}\text { Thickness of over layer } \\
\text { Y1 }(\mathrm{cm})\end{array}$ & $\begin{array}{l}\text { Maximum thickness of hydrate } \\
\text { layer } \mathrm{X} 1(\mathrm{~cm})\end{array}$ & $\begin{array}{l}\text { Hydrate saturation } \\
(\%)\end{array}$ & $\begin{array}{l}\text { Centrifugal acceleration } \\
\text { (g) }\end{array}$ & Slope $\left(^{\circ}\right)$ & Heating modes & $\begin{array}{l}\text { Boundary } \\
\text { constraints }\end{array}$ \\
\hline Case 1 & 15 & 15 & 20 & 50 & 14 & HM1 & $\mathrm{BC} 1$ \\
\hline Case 2 & 7 & 15 & 20 & 50 & 14 & HM3 & BC1 \\
\hline Case 3 & 7 & 15 & 20 & 50 & 14 & HM4 & $\mathrm{BC} 1$ \\
\hline Case 4 & 11 & 12.5 & 40 & 100 & 14 & HM2 & $\mathrm{BC} 2$ \\
\hline Case 5 & 7 & 15 & 40 & 100 & 14 & HM2 & $\mathrm{BC} 3$ \\
\hline Case 6 & 7 & 15 & 40 & 100 & 14 & HM2 & BC1 \\
\hline
\end{tabular}

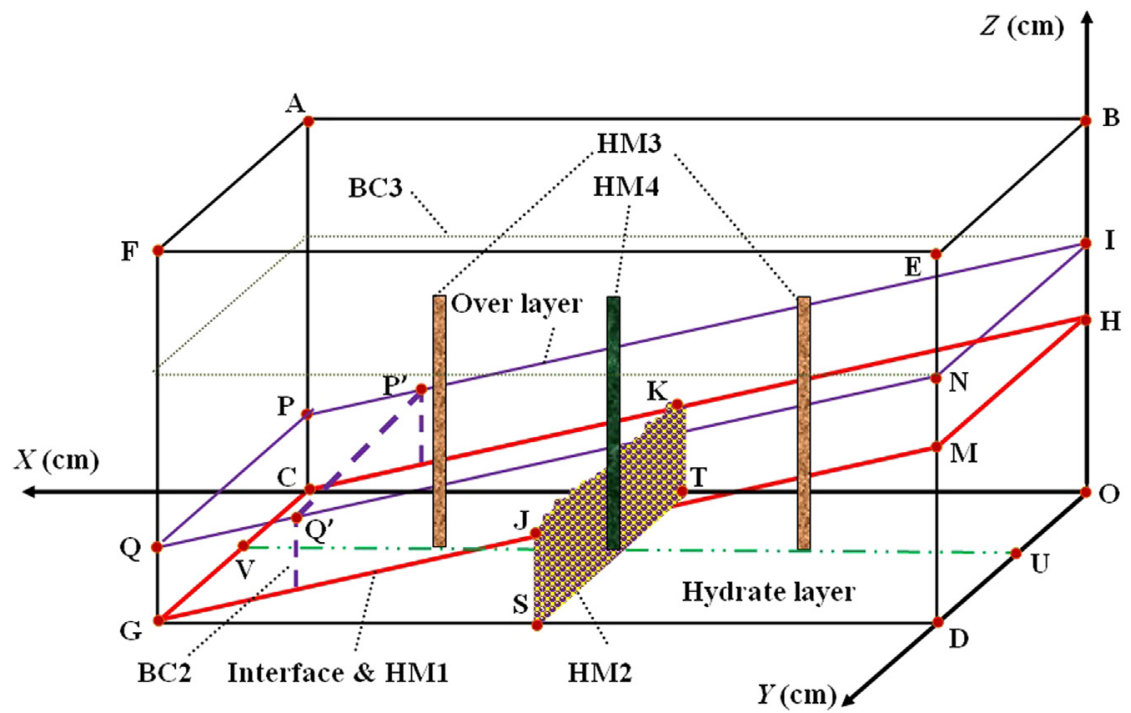

In Cases 2, 3, 5, and 6, the coordinates are as follows:

$\mathrm{O}(0,0,0) ; \mathrm{A}(60,0,40)$; B $(0,0,40) ; \mathrm{C}(60,0,0)$; D $(0,35,0) ; \mathrm{E}(0,35,40)$;

In Case 1, parts of the coordinates are changed as follows:

$\mathrm{I}(0,0,30) ; \mathrm{N}(0,35,30) ; \mathrm{P}(60,0,15) ; \mathrm{Q}(60,35,15)$;

$\mathrm{F}(60,35,40)$; $\mathrm{G}(60,35,0) ; \mathrm{H}(0,0,15) ; \mathrm{I}(0,0,22) ; \mathrm{J}(30,35,7.5) ; \mathrm{K}(30,0,7.5)$; In Case 4, parts of the coordinates are changed as follows:

$\mathrm{M}(0,35,15) ; \mathrm{N}(0,35,22) ; \mathrm{P}(60,0,7) ; \mathrm{Q}(60,35,7) ; \mathrm{S}(30,35,0) ; \mathrm{T}(30,0,0)$;

$\mathrm{U}(0,17.5,0) ; \mathrm{V}(60,17.5,0)$;

$\mathrm{H}(0,0,12.5) ; \mathrm{I}(0,0,23.5) ; \mathrm{J}(25,35,7.5) ; \mathrm{K}(25,0,7.5) ; \mathrm{M}(0,35,12.5)$;

N $(0,35,23.5) ; P(50,0,11) ; Q(50,35,11) ; S(25,35,0) ; T(25,0,0)$.

Fig. 2. The setups in centrifugal tests.

heating efficiencies. Boundary conditions BC1 and BC2 were applied to simulate the fixed toe and free toe of the slope, respectively, and BC1 and BC3 were applied to compare the effect of water depth on the stratum instability. The heating temperature was $70^{\circ} \mathrm{C}$ in Cases $2-6$. The hydrate was dissociated at a temperature of $30{ }^{\circ} \mathrm{C}$ in Case 1 . The degrees of hydrate saturation were $20 \%$ and $40 \%$, respectively. The thicknesses of the over layer were $15,7,7,11,7$, and $7 \mathrm{~cm}$ in Cases $1-6$, respectively. The maximum thicknesses of the hydrate layer were $15,1515,12.5,15$ and $15 \mathrm{~cm}$, respectively. In Case 4 , the maximum thickness of the hydrate layer was changed to keep the slope at $14^{\circ}$ because a gap of $10 \mathrm{~cm}$ was set at the toe of the slope. The lengths of the model ranged from $50 \mathrm{~cm}$ to $60 \mathrm{~cm}$. In Case 5, the water depth was set at $15 \mathrm{~cm}$.

The centrifugal acceleration was $50 \mathrm{~g}$ in Cases $1-3$ and $100 \mathrm{~g}$ in Cases 4-6. The model container walls were smoothed and lubricated using vaseline to reduce the side friction. As the cohesion between the clay and the model wall was only about $1 / 100-1 / 50$ of that of the over layer in the direct shear tests, the friction between the clay and the model container wall only affected the model behavior slightly.

(1) Heating MODES AND BOUNDARY constraints

Hydrate dissociation was caused by heating. The heating modes and positions were varied to investigate the effect of hydrate dissociation zone and to illustrate the slope sliding levels under different boundary constraints. Fig. 2 shows a three-dimensional Cartesian-coordinate system for the model. The hydrate layer was heated with four different heating modes: (i) HM1, the heat from the over layer transferred into the hydrate layer through the interface GCHM; (ii) HM2, a heating band $34 \mathrm{~cm}$ in length, $7.5 \mathrm{~cm}$ in height and $0.2 \mathrm{~cm}$ in thickness was set in the hydrate layer, and the heat transferred through JKTS; (iii) HM3, a heating rod $1 \mathrm{~cm}$ in diameter and $10 \mathrm{~cm}$ in length was placed in the middle of the model, and the heat transferred around the rod; (iv) HM4, two heating rods were placed at $(X, Y, Z)=(20 \mathrm{~cm}, 17.5 \mathrm{~cm}, 0 \mathrm{~cm})$ and $(40 \mathrm{~cm}, 17.5 \mathrm{~cm}, 0 \mathrm{~cm})$, respectively. Three types of boundary constraints were applied in the modeling tests: the free top surface on the over layer (BC1), a gap of $10 \mathrm{~cm}$ preset at the toe of the slope (BC2), and a water layer on the over layer (BC3). Cases 1, 2, and 3 were subjected to different heating modes with the same boundary constraint type BC1, while Cases 4, 5, and 6 were subjected to different boundary constraints with the same heating mode HM2. The effects of boundary constraints and heating modes on the evolution of stratum instability during hydrate dissociation were then investigated.

(2) Transducers AND Arrangements

Transducers were placed along the centerline $(X=30, Y=17.5$, $Z=7.5 \mathrm{~cm}$ ) of the model close to the interface of the two layers, which were used to monitor the pore fluid pressures ranging from $0 \mathrm{kPa}$ to $700 \mathrm{kPa}$ using Drucker PDCR81 pore 
fluid pressure transducers and temperatures ranging from $-30{ }^{\circ} \mathrm{C}$ to $100{ }^{\circ} \mathrm{C}$ using LXT-PT100-A transducers. The probe of the pore pressure transducer measures the pressure of the multiphase gas-water flow when the capillary pressure is relatively small. Assuming the mean radius $r$ of the pore in the clay is $10 \mu \mathrm{m}$, through the Young-Laplace equation (Adamson, $1990)$, the capillary pressure is $2 T \cos \theta / r$, or about $10 \mathrm{kPa}$, here $T$ is the surface tension, $0.07 \mathrm{~N} / \mathrm{m}$ and $\theta$ is the wetting angle, $0^{\circ}$. The water or gas pressure after hydrate dissociation could be one order of magnitude larger than the capillary pressure in the tests (Zhang et al., 2011). Every transducer was calibrated before each test to guarantee the accuracy (Zhang et al., 2015b). Seven soft strings were placed vertically through the soil layers $(10 \mathrm{~cm}$ from the sidewall of the model box) to measure the sliding of the soil layers because the displacement in the soil layer was difficult to measure. The stiffness of the strings was smaller than that of the soil, $E_{\text {string }} 《 E_{\text {soil }}$, the density of the strings was $1.2 \mathrm{~g} / \mathrm{cm}^{3}$, and the radius of the strings was $1 \mathrm{~mm}, R_{\text {string }} 《 L_{\text {slope }}$. Hence the movement of the strings could reflect the slide between the soil layers. A vertical pipe with a diameter of $1.5 \mathrm{~cm}$ was set in the models to measure the inclination of the over layer.

\section{Test results and discussions}

The centrifuge was started and the centrifugal acceleration reached the designated values of $50 \mathrm{~g}$ and $100 \mathrm{~g}$ in $13 \mathrm{~min}$ and 20 min respectively and the temperature of the heating source reached $70{ }^{\circ} \mathrm{C}$. Fig. 3 shows changes in the centrifugal acceleration, $A(g)$, and the temperature of the heating source, $T\left({ }^{\circ} \mathrm{C}\right)$. All the data are expressed in prototype scale.

\subsection{Physical phenomena}

With the development of the heating-induced hydrate dissociation, soil failures would occur when the driving force equaled or exceeded the resistance. In the tests, fractures occurred in the over layer, and distributed at the top of the slopes during hydrate dissociation. The formation of the vertical fractures indicated that the slopes were instable and tensile stresses developed in the over layer. The pipes were inclined even in the over layer. Under the same boundary constraint conditions in Cases $1-3$, the fractures distributed at the upper part of the slopes (i.e. 0-15 $\mathrm{m}$ from the top of the slope along $X$ axis) as shown in Fig. $4 \mathrm{a}-\mathrm{c}$, and the initial main fracture occurred at about $X=5 \mathrm{~m}, X=7.3 \mathrm{~m}$ and $X=7.8 \mathrm{~m}$. More fractures formed due to local relaxation of stresses. As shown in Fig. $4 \mathrm{~d}-\mathrm{f}$, the number of the fractures was the most in Case 4 due to the absence of constraints in the toe, and was less in Case 5 than

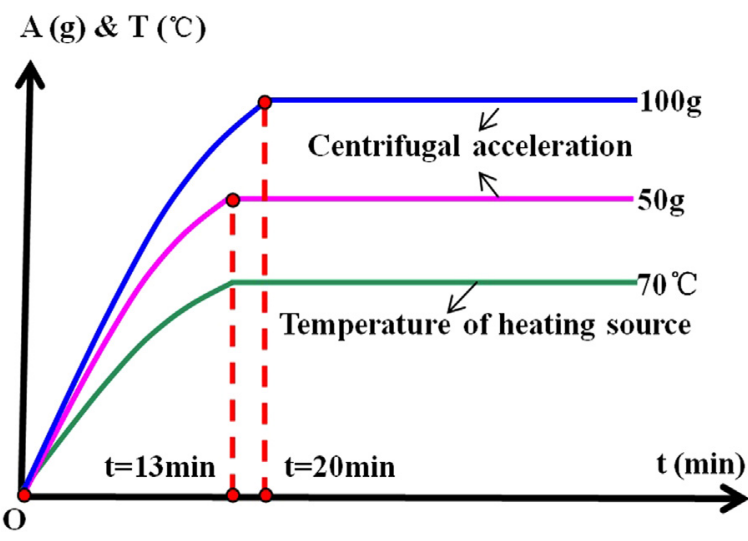

Fig. 3. Centrifugal acceleration and temperature of heating source. that in Case 6 due to the overlying constraint of the water pressure. The initial main fracture occurred at about $X=40 \mathrm{~m}, X=18 \mathrm{~m}$, and $X=19 \mathrm{~m}$. In Case 4, the free toe allowed fractures to form near it. The fractures distributed at certain intervals along the surface of the over layer because the free toe allowed continuous tensile cracks to develop on the entire slope surface. After each test, the thicknesses of all the visible fractures were measured using calipers. The cumulative thicknesses of fractures were about $1.5 \mathrm{~m}$, $1.8 \mathrm{~m}, 2.5 \mathrm{~m}, 12 \mathrm{~m}, 4 \mathrm{~m}$, and $5.5 \mathrm{~m}$ in Cases $1-6$, respectively. A certain depth of water was gathered at the toe of the slope from the hydrate dissociation zone during the tests.

After each test, the middle section along the $X$ axis of the soil layers was excavated. Visible layered fractures with thicknesses of 0-0.5 $\mathrm{m}$ in Cases 1-3 and $0-1 \mathrm{~m}$ in Cases 4-6 developed at the interface between the over layer and the hydrate layer in Fig. 5. The formation mechanisms of layered fractures are as follows. The released gas and water were enclosed in the hydrate dissociation zone, leading to the development of excess pore fluid pressure, and hence the decrease of the strength, stiffness and effective stress of the soil layer in the dissociation zone. The dissociated hydrate layer was compressed due to the self-weight; the over layer moved upwards under the high pore fluid pressure. Then layered fractures initiated and developed accompanying the seepage of the pore fluid into the gap. Layered fractures expanded with the increase of the hydrate dissociation zone (Zhang et al., 2015b).

After the tests, the soils were excavated and the thicknesses of the soil layers and the bending of strings were measured. It showed that the soil layers could be separated clearly due to the softening of the hydrate layer after dissociation and the existence of layered fractures. Bending of strings occurred, and the bending points were close to the interface of the soil layers (Fig. 6). The heterogeneous deformation consisted of settlement and sliding in the hydrate layer and the over layer. The soft strings moved with the soils, and the differential deformations between the layers led to the bending of the strings.

\subsection{Basic data}

The temperature and pressure were recorded from the start of heating to the shutting down of the centrifuge in the tests. The slopes of the soil layers became gentler by about $4-10^{\circ}$ at the end of tests. The changes in slopes were caused by the heterogeneous settlement and the sliding between the soil layers during hydrate dissociation. About one half of the soil was excavated to observe the cross sections along the length after the test of Case 3. The thicknesses of the hydrate layer and the over layer were measured as shown in Fig. 7. The settlement was larger at the upper part of the hydrate layer than that at the lower part due to the weightinduced compression and thrust from the soft hydrate layer after dissociation, while the thickness of the over layer changed little. The hydrate dissociation zones expanded to $2.5 \mathrm{~m}, 30 \mathrm{~m}, 26 \mathrm{~m}$, $26 \mathrm{~m}, 33 \mathrm{~m}, 32 \mathrm{~m}$, respectively.

Fig. 8 presents the fluid pressure evolution under different heating modes at $50 \mathrm{~g}$ (Cases $1-3$ ). The pore fluid pressure at the interface increases initially, then keeps stable for a certain period, and finally goes down due to the release of pore fluid from the layered fractures. The increasing rate is related to the rate of heating. The maximum pore fluid pressures in Cases 1-3 are $110 \mathrm{kPa}, 130 \mathrm{kPa}$, and $100 \mathrm{kPa}$, close to those of the total stresses (self-weight of the soil) of the over layer of $130 \mathrm{kPa}, 60 \mathrm{kPa}$, and $60 \mathrm{kPa}$, respectively. In Case 1 , the vertical displacement is about $0.75 \mathrm{~m}$ along the length due to the uniform heating from the interface to the hydrate layer. In Cases 2 and 3, sinking occurs in the upper parts and uplifting occurs in the lower parts due to the slide and the squeezing of soft soils in the hydrate dissociation zone. 
a

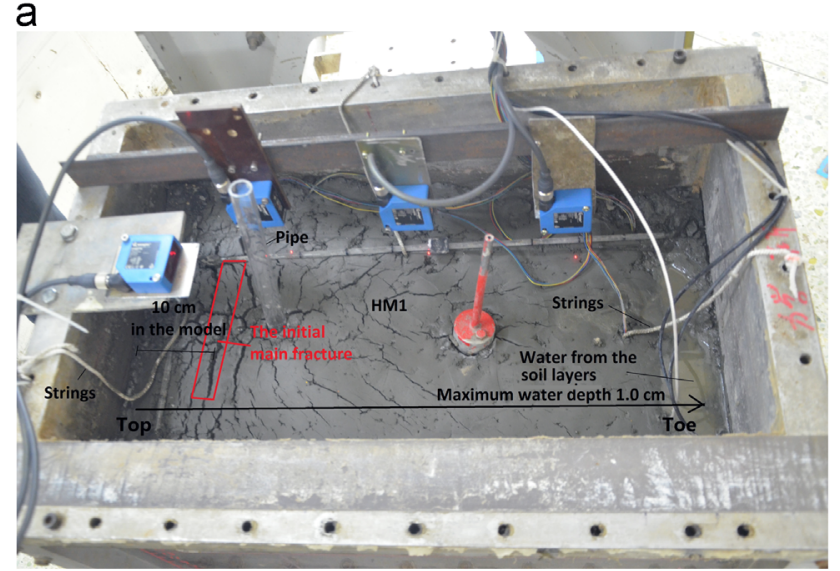

C

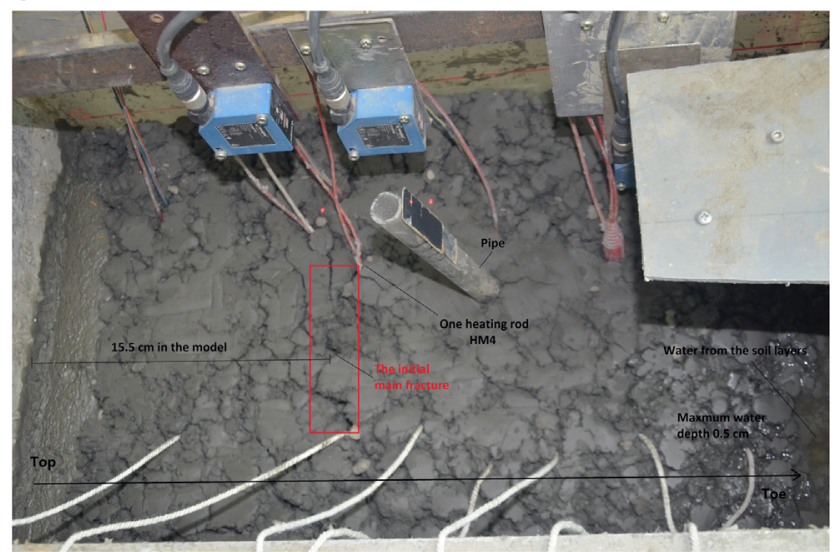

e

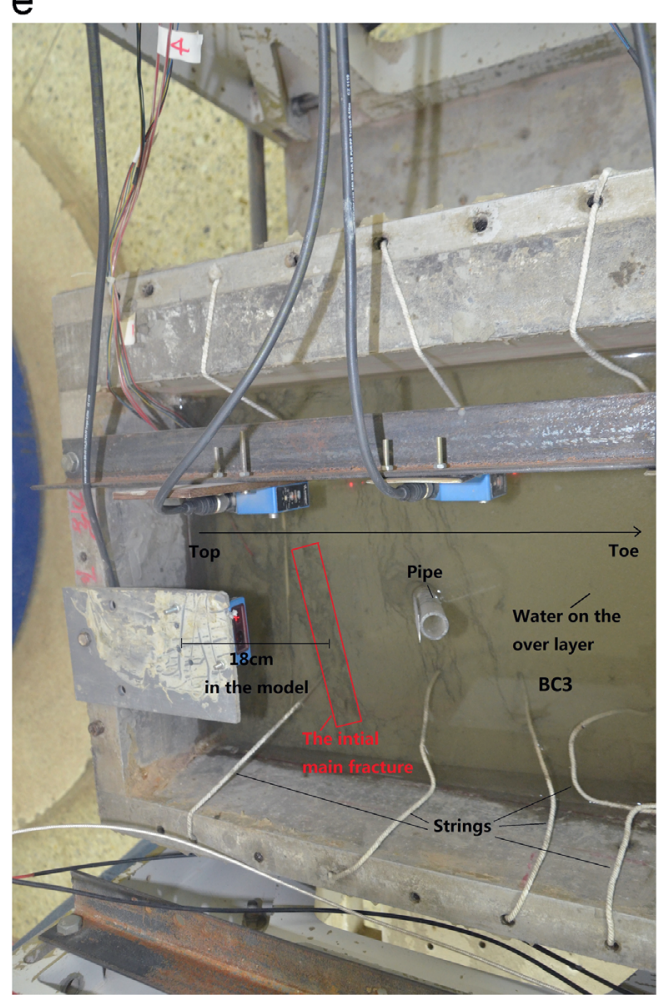

b

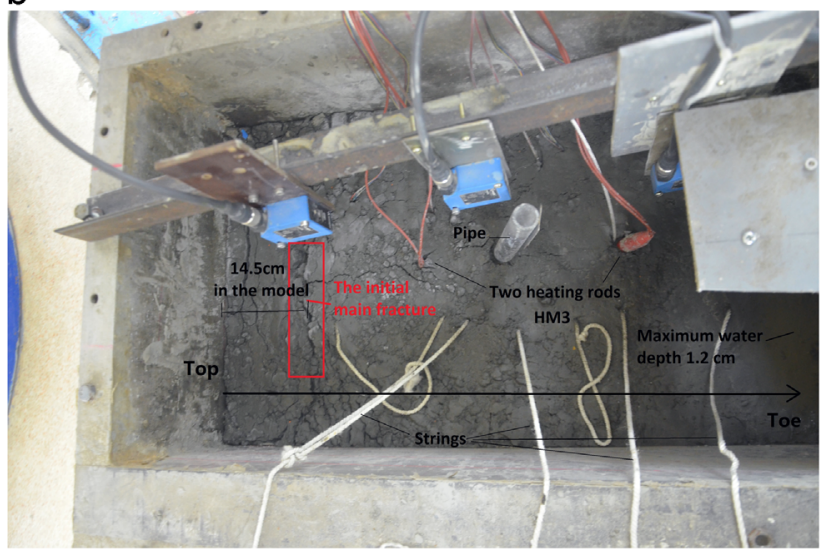

d

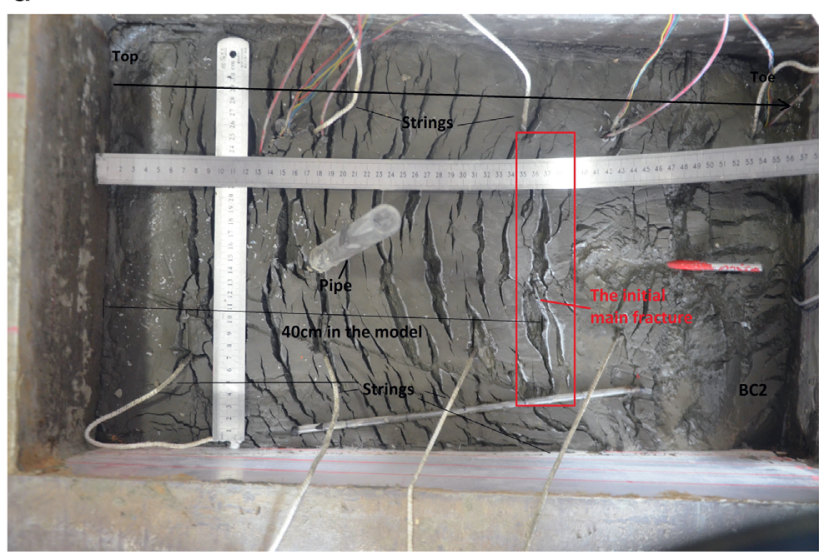

f

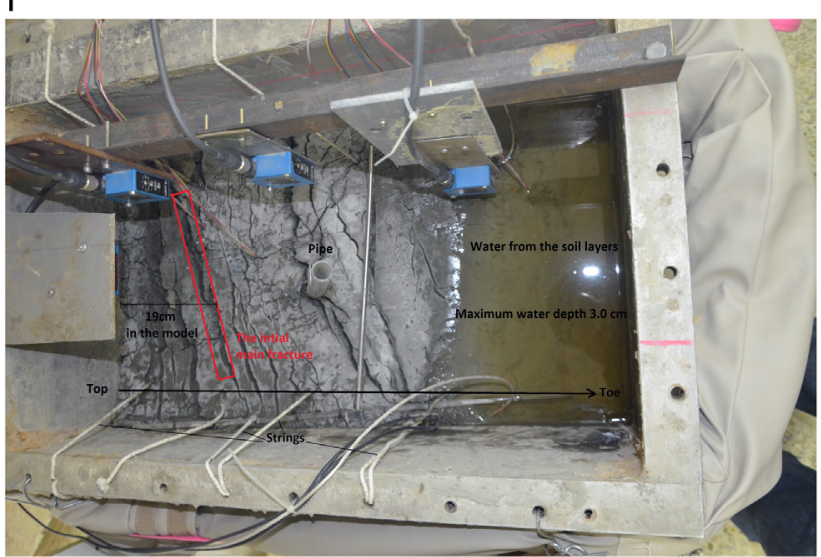

Fig. 4. Fractures at the top surface of the slope during centrifuge tests. (a) Case 1-HM1, BC1, 50g. (b) Case 2-HM3, BC1, 50g. (c) Case 3-HM4, BC1, 50g. (d) Case 4-HM2, BC2, 100g. (e) Case 5-HM2, BC3, 100g. (f) Case 6-HM2, BC1, 100g. 


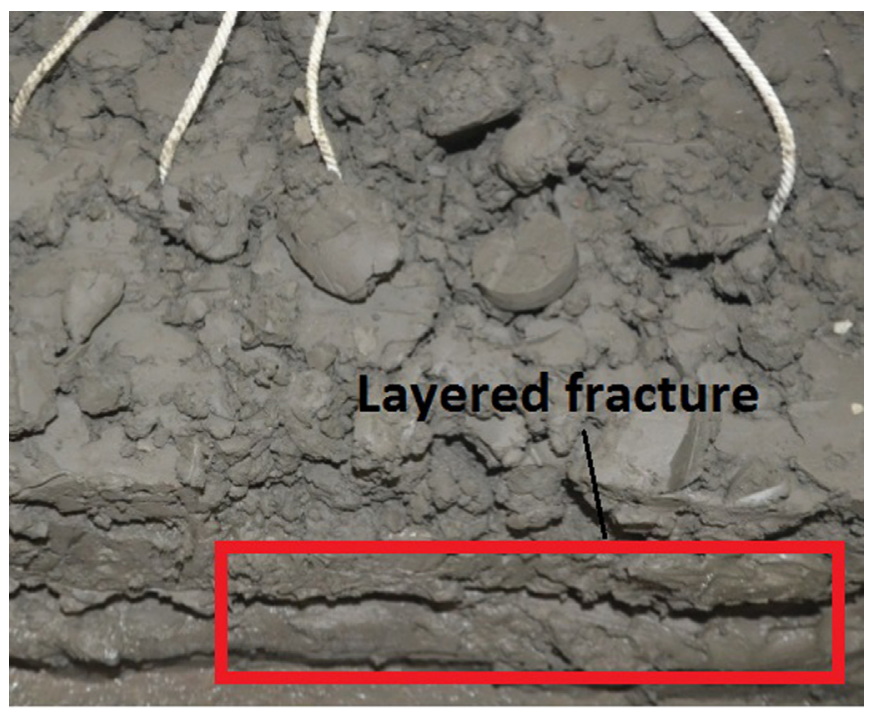

Fig. 5. Layered fractures.

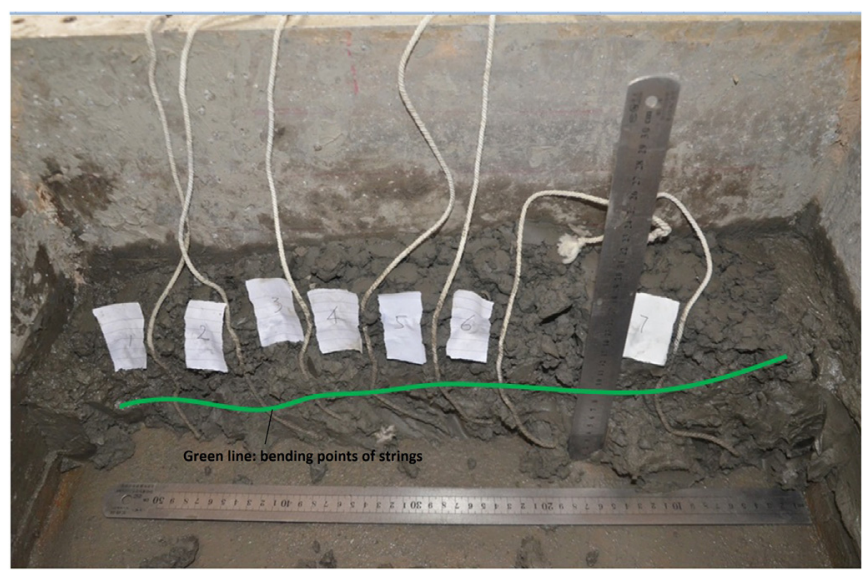

Fig. 6. Interface and sliding plane between soil layers.

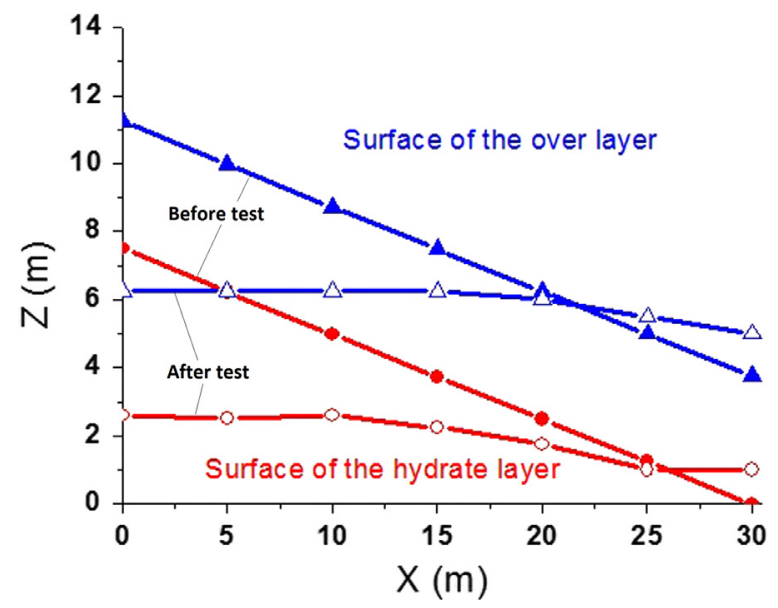

Fig. 7. Thicknesses of the hydrate layer and the over layer.

The horizontal displacements along the length are nonlinear. In Case 1, the displacement increases from the top to the toe of the slope. In Cases 2 and 3, the displacements are larger in the middle due to the presence of an un-dissociated zone which provides high strength and stiffness.

The results of the tests at $100 \mathrm{~g}$ (Cases 4-6) with different boundary conditions are shown in Fig. 9. The pore fluid pressures increase initially, and then decrease very slowly. The maximum pore fluid pressures in Cases 4, 5, and 6 are $180 \mathrm{kPa}, 220 \mathrm{kPa}$, and $160 \mathrm{kPa}$, close to he total stresses of the over layer of $190 \mathrm{kPa}$, $217 \mathrm{kPa}$, and $120 \mathrm{kPa}$, respectively. The vertical displacement in Case 4 is the largest because the free toe provides the weakest constraint allowing a large displacement at the lower part. The vertical displacement in Case 5 is larger than that in Case 6 because the additional water weight is applied on the over layer. The horizontal displacement in Cases 4 is about $5.0 \mathrm{~m}$ in the lower part of the slope, and $1.0 \mathrm{~m}$ in the upper part. The horizontal displacement in Case 5 decreases from the top to the toe of the slope due to the stronger constraint of the water in the lower part. The horizontal displacement in Case 6 increases from the top to the toe of the slope with a continuous deformation along the length direction. The leap of the horizontal displacement can be explained by the local heterogeneity in the soil layer during hydrate dissociation. The measured deformations in Figs. 8 and 9 cover the length range from $X=10 \mathrm{~m}$ to $X=50 \mathrm{~m}$ due to the side friction effect.

\section{Formulations of the physical processes}

According to the physical phenomena and basic data, heat transfer leads to hydrate dissociation and weakening of the soil, accompanied by seepage of fluids and deformation of the soil. As a consequence, soil failure occurs. Decoupled mathematical formations are presented to describe these physical effects. First, the analytical solution of the hydrate dissociation expansion was obtained. Second, the vertical displacement of the soil layers in seepage and consolidation was calculated; and through the comparison with the test results, the effect of the slide on the soil deformation was discussed. Third, under the mechanism of layered fractures, the critical condition of stratum instability was presented based on a limit equilibrium method. Under this condition, the geometrical scale of stratum instabilities will be much different from that of landslides or marine slides.

\subsection{Heat transfer and phase transformation}

First, the evolution of hydrate dissociation zone was solved. The hydrate dissociation and heat conduction evolve over time at a heating temperature of $70^{\circ} \mathrm{C}$. Firstly, the temperature of the sediment surrounding a thermal source increases, causing the hydrate to dissociate into water and liquid THF. When the phase equilibrium temperature is reached, a hydrate dissociation zone and a non-dissociated zone form and these two zones are divided by the dissociation front. Secondly, the liquid THF is gasified when the gasification temperature is reached, and so a gasification zone forms and is separated from the hydrate dissociation zone by the gasification front. These two fronts all expand with time. Hence three zones, Z1, Z2 and Z3, and two fronts, F1 and F2, are present in the hydrate sediment (Zhang et al., 2014).

Under heating mode HM1 (Fig. 10a), just the hydrate dissociation front F1 and two zones Z1, Z2 are formed. The heat conducts from the over layer to the hydrate layer due to the temperature difference between the two soil layers. Under heating modes HM2, HM3 and HM4, the hydrate dissociation zone can be regarded to expand as shown in Fig. 10b. HM2 leads to the hydrate dissociation along the $X$ axis; the fluid seepage and soil deformation occur in a rectangular zone with the expansion of the dissociation zone. HM3 leads to the hydrate dissociation in two stages. In the first stage, the dissociation zone expands around the heating rod axisymmetrically and the local fluid seepage and soil deformation occur in a circular zone. In the second stage, the dissociation zone reaches the side wall and changes to fingering expansion. In HM4 
a

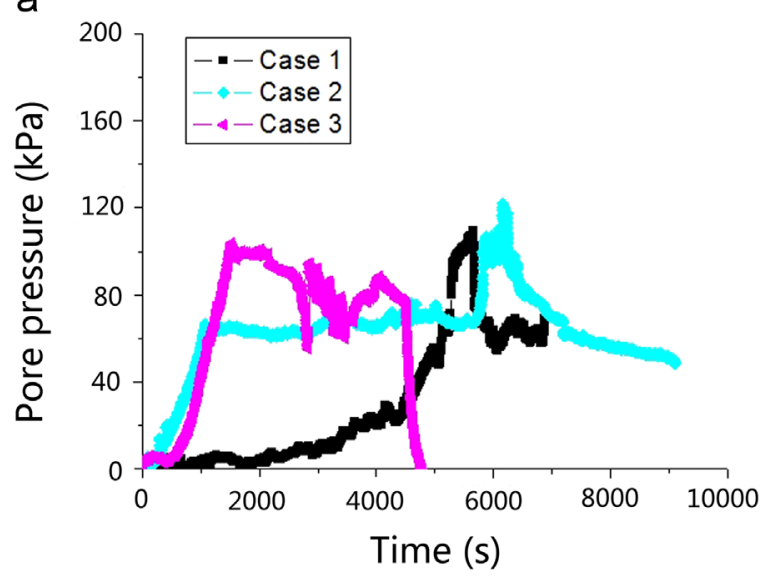

b

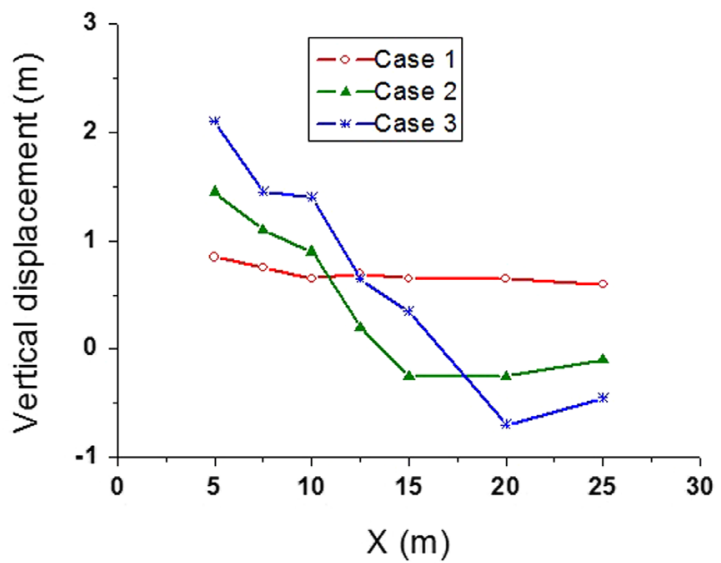

C

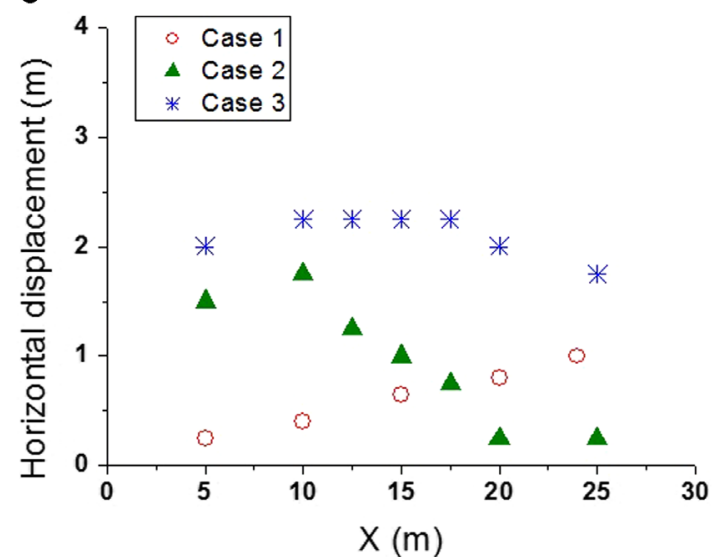

Fig. 8. Pore pressures, vertical and horizontal displacements in Cases 1-3. (a) Pore pressures. (b) Vertical displacements. (c) Horizontal displacements.

two rods provide more heat and cross heating, leading to more rapid expansion of the dissociation zone.

The heat transfer process has two transformation fronts, i.e. a hydrate dissociation front and a liquid THF gasification front. An one-dimensional solution to the expansion of hydrate dissociation front $F 1$ can be expressed as:

$X_{e 1}=\left(\xi_{e 1} \kappa_{1} t\right)^{1 / 2}$

where $X_{e 1}, \kappa_{1}$, and $\xi_{e 1}$ represent the length of the hydrate dissociation zone, the thermal diffusivity, and a self-similarity parameter, respectively, and can be obtained by a Newtonian iterative method. The thermal parameters of water, liquid THF, gas THF, and THF hydrate are referred to Zhang et al. (2014), and parameters for clay (i.e. a specific heat of $800 \mathrm{~J} / \mathrm{kg} / \mathrm{K}$ and a thermal conductivity coefficient of $2.0 \mathrm{w} / \mathrm{m} / \mathrm{K}$ ) are referred to Waite et al. (2009).

The hydrate dissociation zones expand to $2.3 \mathrm{~m}, 28 \mathrm{~m}, 24 \mathrm{~m}$, $25 \mathrm{~m}, 32 \mathrm{~m}, 30 \mathrm{~m}$, respectively. Table 2 gives the theoretical and measured lengths of the hydrate dissociation zone. The measured length is slightly larger. The reason may be that the convective heat transfer during fluid seepage increases the expansion of the hydrate dissociation, which is not considered in the theoretical model.

\subsection{Seepage and consolidation}

Second, the seepage of fluids and the consolidation of soil after hydrate dissociation were analyzed. Assume that the pore fluid in the hydrate dissociation zone percolates into the layered fractures and is partially drained through the seepage path at the toe. In the decoupling method, the seepage and heat transfer are analyzed first; then the deformation Sof the soil layers are calculated. Before the soil failure, the deformation can be analyzed based on onedimensional compression and deformation principle (Scott, 1986; Lu et al., 2008a, 2008b) considering the self and over-weight as external loads. Here, the soil is considered to be a continuous and homogeneous mass with no fractures, and behaves as a linear elastic material on a horizontal plane.

The self-weight induced deformation of the hydrate layer and the over layer is:

$S_{1}=\int_{0}^{H} \frac{\sigma^{\prime}(z)}{E_{s 1}} d z=\frac{\left(\rho_{s 1}-\rho_{w}\right) N g}{2 E_{s 1}} \cdot H^{2}$

The deformation of the hydrate layer induced by the overweight load is:

$S_{2}=\frac{p H}{E_{s 1}}=\frac{\rho_{s 2} N g h_{2}}{E_{s 1}} H$

Then the total consolidation deformation before soil failure is as follows:

$S=S_{1}+S_{2}$

where $\sigma^{\prime}$ is the effective stress in the hydrate layer; $\rho_{s 1}$ represents the density of saturated soils in the hydrate layer after hydrate dissociation; pis the weight of the over layer; $H$ is the thickness somewhere of the hydrate layer; $\rho_{S 2}$ and $h_{2}$ are the density and thickness of the over layer, respectively. The compression modulus $E_{s 1}$ of the hydrate layer after hydrate dissociation is $1.6 \mathrm{MPa}$ by the oedometer test.

The vertical displacements by the soil weight are estimated using Eqs. (2)-(4), and the results are linear along the length. The 


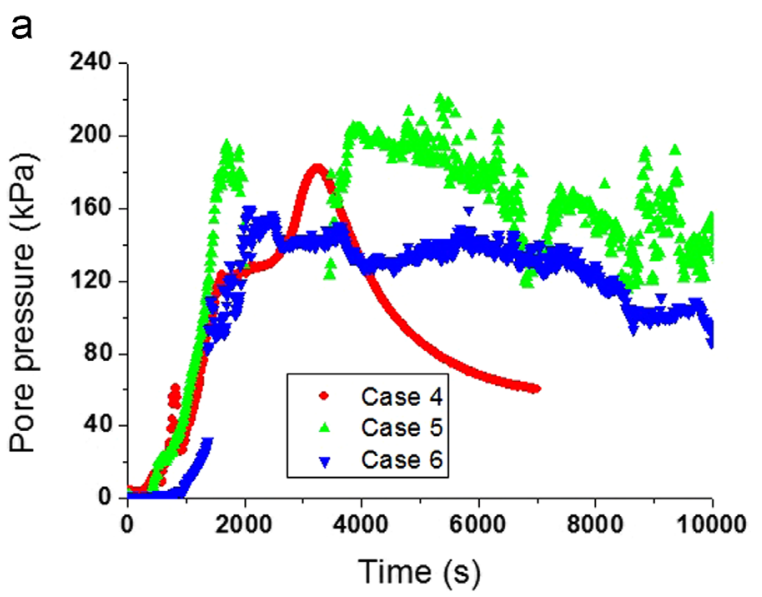

C

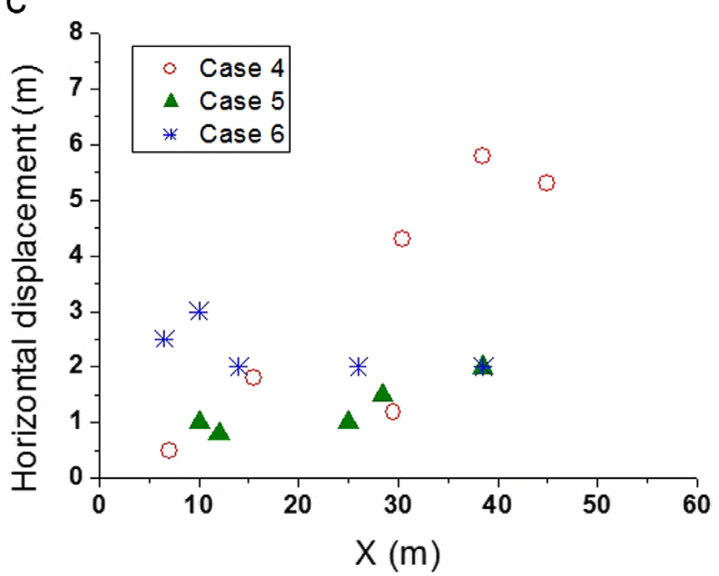

b

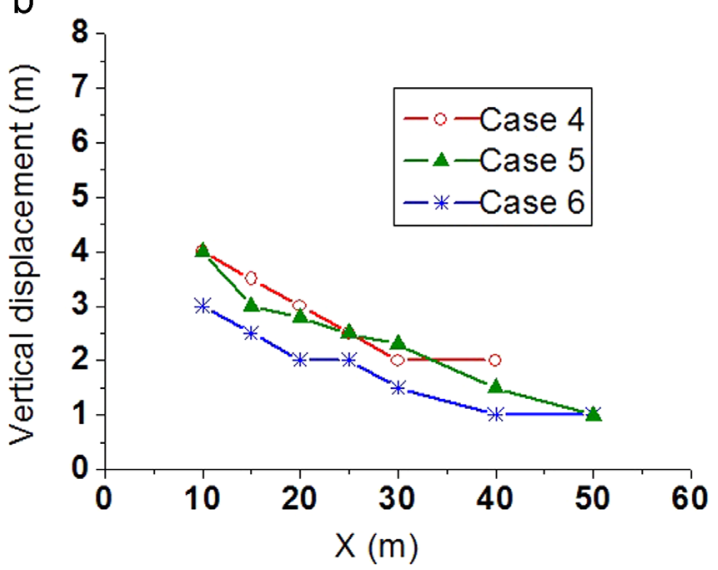

Fig. 9. Pore pressures, vertical and horizontal displacements in Cases 4-6. (a) Pore pressures. (b) Vertical displacements. (c) Horizontal displacements.

test results are nonlinear and have an inflection point as shown in Fig. 11. The main reason is that the slide of the over layer carries certain soil downwards, squeezes the soil, and forces the vertical uplift at the toe of the slope. Further the formulation of accurate vertical displacements should include two physical effects: the seepage and consolidation, and stratum failures such as sliding and squeezing of soil layers.

\subsection{Failure and sliding based on the mechanism of layered fracture}

Third, the stress field and the critical condition of soil failure after the hydrate dissociation and seepage and consolidation were analyzed. The physical processes can be described as follows based on the phenomena and data of the centrifugal tests. In the initial stage of the hydrate dissociation, the shear strength of soil is large enough to keep the slope stable. Small horizontal and vertical displacements develop around the dissociation zone accompanying fluid seepage as water flows to the toe of the slope. With the expansion of the hydrate dissociation length, layered fractures develop at the interface between the hydrate layer and the over layer, reducing the shear strength at the interface greatly. Then the local weight of the over layer is supported by the pore fluid pressure and the soil layers move along the slope.

When the expansion of hydrate dissociation exceeds the critical length, the shear strength at the lower part of the slope over the hydrate dissociation zone is approached accompanied by the soil tensile failure at the upper of the slope. Then large compression deformation of the soil layer over the hydrate dissociation zone occurs due to the soil weight, leading to the sliding between the soil layers and the formation of the initial main tensile fractures.
Finally, more fractures develop until a new mechanical equilibrium is reached along the slope.

Based on the above analysis, a limit equilibrium method is used to analyze the failure process, as shown in Fig. 12. It is assumed that in the over layer, the shear failure occurs at the lower front of dissociation zone and the tensile fracture forms at the upper front of dissociation zone simultaneously with the critical hydrate dissociation length $l_{c r}$.

Assume the shear strength of soils follows the Mohr-Coulomb criterion (Schofield and Worth, 1968):

$\tau_{f}=\sigma^{\prime} \tan \phi+c$

The stress condition at the failure state is as follows:

$\frac{\sigma_{1}^{\prime}+c \cot \varphi}{\sigma_{3}^{\prime}+c \cot \varphi}=\tan ^{2}\left(45^{\circ}+\varphi / 2\right)$

where, $\sigma^{\prime}, c$, and $\phi$ represent the effective stress, cohesion and internal frictional angle of the soil, respectively. According to the Rankine earth pressure equation and mechanical equilibrium along the slope direction over the hydrate dissociation zone, the following relationship can be obtained:

$\rho_{s 2} g l_{c r} \sin \alpha=\rho_{s 2} g h_{2} \tan ^{2}\left(45^{\circ}+\varphi / 2\right) / 2+2 c \tan \left(45^{\circ}+\varphi / 2\right)$

The critical length can be deduced from (7):

$l_{c r}=\frac{\rho_{s 2} g h_{2} \tan ^{2}\left(45^{\circ}+\varphi / 2\right) / 2+2 c \tan \left(45^{\circ}+\varphi / 2\right)}{\rho_{s 2} g \sin \alpha}$

In the centrifuge test (prototype scale), the critical length is as follows: 
a

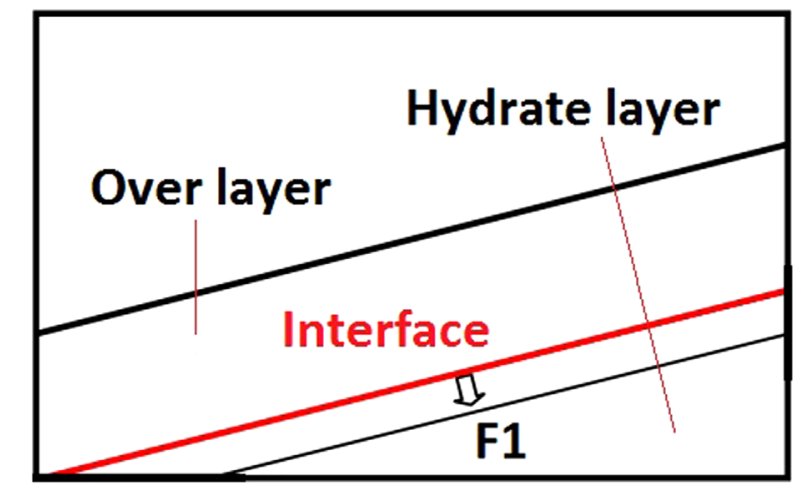

b

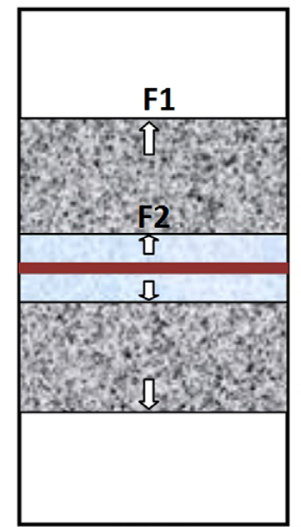

HM2

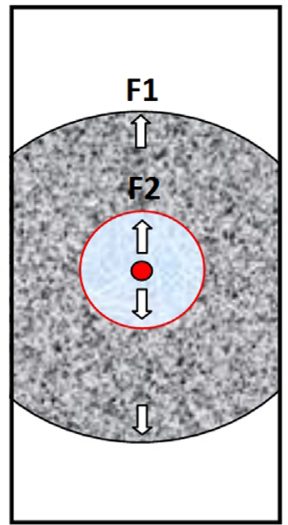

HM3

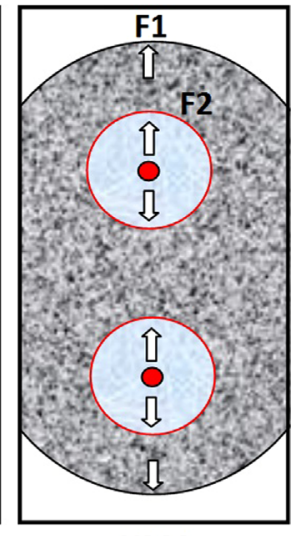

HM4
Fig. 10. Hydrate dissociation under different heating modes. (a) HM1. (b) HM2, HM3, HM4.

Table 2

Lengths of theoretical and measured hydrate dissociation zone.

\begin{tabular}{lcccccc}
\hline Cases & Case 1 & Case 2 & Case 3 & Case 4 & Case 5 & Case 6 \\
\hline $\begin{array}{l}\text { Measure length } \\
(\mathrm{m})\end{array}$ & 2.5 & 30 & 26 & 26 & 33 & 32 \\
$\begin{array}{l}\text { Calculated length } \\
(\mathrm{m})\end{array}$ & 2.3 & 28 & 24 & 25 & 32 & 30 \\
\hline
\end{tabular}

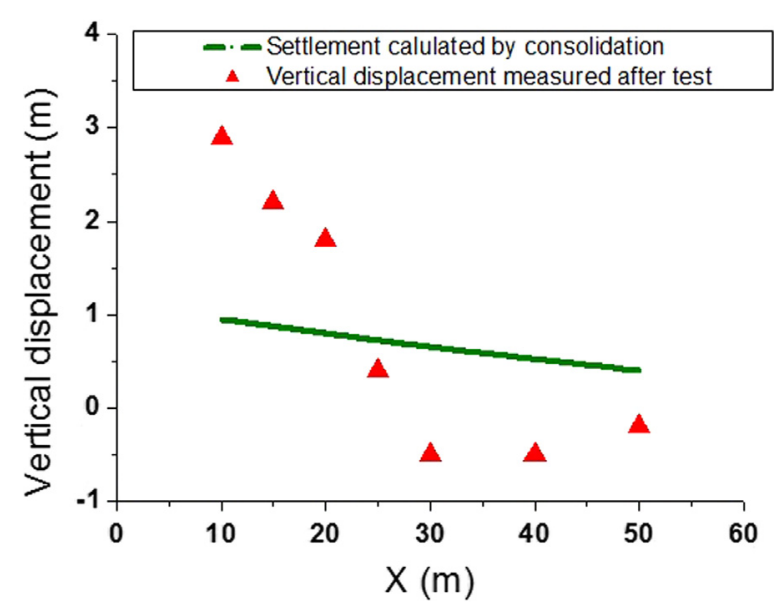

Fig. 11. Comparison of deformations before and after stratum failure.

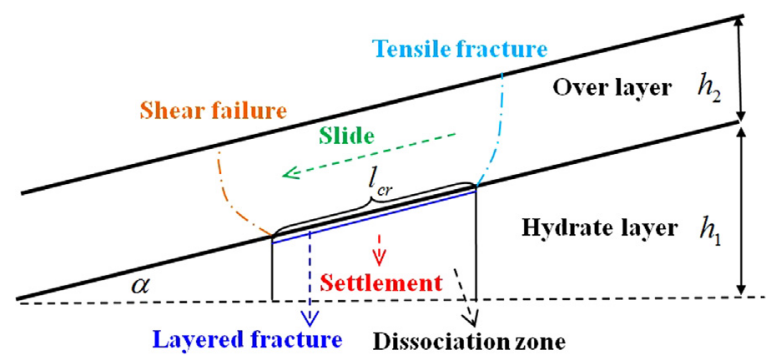

Fig. 12. Failure modes based on layered fractures and limit equilibrium analysis.

Table 3

Sites, thickness of fractures and maximum displacements of strings in the soil layers.

\begin{tabular}{llllll}
\hline Cases & $X_{t}(\mathrm{~m})$ & $X_{m}(\mathrm{~m})$ & $\Delta d_{t}(\mathrm{~m})$ & $\Delta d_{m}(\mathrm{~m})$ & $s(\mathrm{~m})$ \\
\hline Case 2 & 8 & 7.3 & 2.5 & 1.8 & 1.8 \\
Case 3 & 8 & 7.8 & 2.5 & 2.5 & 2.5 \\
Case 5 & 19.5 & 18 & 6 & 4.0 & 4.5 \\
Case 6 & 19.5 & 19 & 6 & 5.5 & 6 \\
\hline
\end{tabular}

$l_{c r}=\frac{\rho_{s 2} N g h_{2} \tan ^{2}\left(45^{\circ}+\phi / 2\right) / 2+2 c \tan \left(45^{\circ}+\phi / 2\right)}{\rho_{s 2} N g \sin \alpha}$

Then the compression deformation of the over layer can be integrated along the length of the critical failure:

$\Delta d=\int_{0}^{l_{c r}} \frac{\sigma^{\prime}(x)}{E_{s 2}} d x=\frac{\rho_{s 2} N g \sin \alpha}{2 E_{s 2}} \cdot l_{c r}^{2}$

where $\rho_{s 2}$ represents the density of the over layer. The compression modulus $E_{s 2}$ of the over layer is $16 \mathrm{MPa}$ by the oedometer test.

Substituting the test parameters into Eqs. (9) and (10), $l_{c r}$ in Cases 2, 3, 5, and 6 are $14 \mathrm{~m}, 14 \mathrm{~m}, 21 \mathrm{~m}, 21 \mathrm{~m}, \Delta d$ are $2.5 \mathrm{~m}, 2.5 \mathrm{~m}$, $6 \mathrm{~m}, 6 \mathrm{~m}$, respectively. The critical condition was reached during the hydrate dissociation in the centrifugal tests because the critical lengths were less than that of the dissociation zone. The deformation and failure in Case 1 and Case 4 are more complex and not discussed here.

Here, it is regarded that the deformation along the critical length leads to the formation of the fractures after the critical condition is reached as in Fig. 12. In Table 3, $\Delta d_{t}$ and $\Delta d_{m}$ represent the calculated deformation and summation of the fracture thicknesses measured after the tests. $t$ and $m$ indicate the theoretical results and the measured results, respectively. $X_{t}$ represents the calculated $X$ value of the initial main fracture; the failure zone $l_{c r}$ is considered in the centre of the model length direction; $L$ is the horizontal length of the slope $X_{t}=\left(L-l_{c r} \cos \alpha\right) / 2 ; X_{m}$ represents the measured $X$ value of the first fracture during hydrate dissociation; $s$ is the maximum horizontal displacement measured by the strings. From the comparison, the measured maximum sliding, the calculated deformation along the critical length of the slope, and the summation of the thicknesses of the fractures were close (as in Table 3). The forecasting Xs of the first fractures are slightly less than the measured values with errors of $9 \%, 3 \%, 8 \%$ and $3 \%$, respectively. The result indicates that the surface fractures are formed mainly due to the deformation of the over layer along the critical length.

The expressions based on the mechanism of the layered fracture and the limit mechanical equilibrium describe the decoupling physical processes of the stratum instability, and the critical condition based on layered fractures during hydrate dissociation provide an engineering reference under similar geological and geotechnical conditions. 


\section{Conclusions}

Through a series of centrifugal tests, the physical mechanisms of soil stratum instability during thermal induced hydrate dissociation are investigated considering the effects of heating modes and boundary constraint conditions. The prototype scales are $30 \mathrm{~m}$ and $60 \mathrm{~m}$ in $50 \mathrm{~g}$ and $100 \mathrm{~g}$, respectively. The soil layers, i.e. the hydrate layer and the over layer, were prepared using a clay from the Dongsha hydrate zone in South China Sea, which reflected realistic geological and geotechnical properties.

In a small slope of $14^{\circ}$, the soil responses such as the formations of fractures, layered fractures, settlement and sliding are observed, which are different from conventional landslides. During the hydrate dissociation, the hydrate layer softens, and the pore fluid pressure exceeds the total stress of the over layer, leading to the formation of layered fracture between the hydrate layer and the over layer.

Though different heating modes and boundary constraints are adopted, the test results show similar characteristics that at the initial stage of hydrate dissociation, local small deformation occurs due to the softening of the hydrate layer under the soil weight, while large sliding accompanying fractures occurs when the dissociation zone reaches a critical length.

Decoupling formulations are presented to describe the heat transfer containing hydrate dissociation, seepage and consolidation of the soil, and critical condition of soil failures based on the mechanism of layered fracture and the limit equilibrium method.

The critical length of the stratum failure is about one half of the horizontal length of the slope in the centrifugal tests. The calculated sliding values are $2.5 \mathrm{~m}$ in $50 \mathrm{~g}$, and $6.0 \mathrm{~m}$ in $100 \mathrm{~g}$, about $1 / 10$ length of the slope, in agreement with the summation of the thicknesses of the fractures. The results provide a reference for hydrate exploitation in the hydrate layer and oil and gas exploitation under the hydrate layer.

\section{Acknowledgements}

This study is funded by China Geological Survey (No. GZH201100311), National Natural Science Foundation of China (Nos. 51239010, 11102209), and CNPC-CAS cooperation project (No. 2015A-4813).

\section{References}

Adamson, A.W., 1990. Physical Chemistry of Surfaces. John Wiley \& Son Inc., USA. Borja, R.I., White, J.A., Liu, X.Y., et al., 2012. Factor of safety in a partially saturated slope inferred from hydro-mechanical continuum modeling. Int. J. Numer. Anal. Methods Geomech. 36, 236-248.

Briaud, J.L., Chaouch, A., 1997. Hydrate melting in soil around hot conductor. ASCE J.
Geotech. Geoenviron. Eng. 123 (7), 645-653.

Hyodo, M., Li, Y.H., Yoneda, J., et al., 2014. Effects of dissociation on the shear strength and deformation behavior of methane hydrate-bearing sediments. Mar. Pet. Geol. 51, 52-62.

Jiang, M.J., Chen, H., Tapias, M., et al., 2014. Study of mechanical behavior and strain localization of methane hydrate bearing sediments with different saturations by a new DEM model. Comput. Geotech. 57, 122-138.

Kayen, R.E., Lee, H.J., 1991. Pleistocene slope instability of gas hydrate-laden sediment on the Beaufortsea margin. Mar. Geotechnol. 10, 125-141.

Kimoto, S., Oka, F., Fushita, T., 2010. A chemo-thermo-mechanically coupled analysis of ground deformation induced by gas hydrate dissociation. Int. J. Mech. Sci. 52, 365-376.

Klar, A., Soga, K., Ng, M.Y.A., 2010. Coupled deformation-flow analysis for methane hydrate extraction. Geotechnique 60 (10), 765-776.

Kwon, T.H., Cho, G.C., 2012. Submarine slope failure primed and triggered by bottom water warming in oceanic hydrate-bearing deposits. Energies 5, 2849-2873.

Kwon, T.H., Cho, G.C., Santamarina, J.C., 2008. Gas hydrate dissociation in sediments: pressure-temperature evolution. Geochem. Geophys. Geosyst. 9, Q03019.

Kwon, T.H., Oh, T.M., Cho, Y.W., et al., 2013. Geomechanical and thermal responses of hydrate bearing sediments subjected to thermal simulation: physical modeling using a geotechnical centrifuge. Energy Fuels 27, 4507-4522.

Lu, X.B., Wang, S.Y., Cui, P., 2008b. Cracks in saturated sand. In: Slopes-Chen, et al. (Eds.), Landslides and Engineered. Taylor \& Francis Group, London, pp. 263-266.

Lu, X.B., Zhang, X.H., Hu, G.H., 2013. Centrifugal experiment on stratum instability and failure process due to gas hydrate dissociation. In: Wu, Qi (Eds.), Global View of Eng. Geol. Environment. Taylor \& Francis Group, London, pp. 197-200.

Lu, X.B., Wang, L., Wang, S.Y. et al., 2008a. Study on the mechanical properties of THF hydrate deposit. 18th Proc. ISOPE, Vancouver, pp. 57-60.

Schofield, A.N., Worth, C.P., 1968. Critical State Soil Mechanics. McGraw-Hill, London, pp. 144-163.

Scott, R.F., 1986. Solidification and consolidation of a liquefied sand column. Soils Found. 26 (4), 23-31.

Sha, Z.B., Liang, J.Q., Zhang, G.X., et al., 2015a. A seepage gas hydrate system in northern South China Sea: seismic and well log interpretations. Mar. Geol. 366, 69-78.

Sha, Z.B., Liang, J.Q., Su, P.B., et al., 2015b. Natural gas hydrate accumulation elements and drilling results analysis in the eastern part of the Pearl River Mouth Basin. Earth Sci. Front. 22 (6), 125-135, in Chinese.

Song, Y.C., Yang, L., Zhao, J.F., et al., 2014. The status of natural gas hydrate research in China: a review. Renew. Sustain. Energy Rev. 31, 778-791.

Sultan, N., Cochonat, P., Foucher, J.P., et al., 2004. Effect of gas hydrates melting on seafloor slope instability. Mar. Geol. 213, 379-401.

Tan, Q.M., 2011. Dimensional Analysis: with Case Studies in Mechanics. SpringerVerlag Berlin Heidelberg, Berlin, Heidelberg.

Taylor, 1995. Geotechnical Centrifuge Technology. Blackie Academic, London.

Waite, W.F., Santamarina, J.C., Cortes, D.D., 2009. Physical properties of hydratebearing sediments. Rev. Geophys. 47, 1-38.

Xu, W., Germanovich, L.N., 2006. Excess pore pressure resulting from methane hydrate dissociation in marine sediments: a theoretical approach. J. Geophys. Res. 111, B011104.

Yun, T.S., Santamarina, J.C., Ruppel, C., 2007. Mechanical properties of sand, silt, and clay containing tetrahydrofuran hydrate. J. Geophys. Res. 112, B04106.

Zhang, X.H., Lu, X.B., Li, Q.P., 2011. Formation of layered fracture and outburst during gas hydrate dissociation. J. Pet. Sci. Eng. 76 (3-4), 212-216.

Zhang, X.H., Lu, X.B., Zheng, Z.M., et al., 2014. Heat-induced evolution of phase transformations in tetrahydrofuran hydrate-bearing sediment. J. Heat. Transf.Trans. ASME 136, 052002

Zhang, X.H., Lu, X.B., Shi, Y.H., et al., 2015a. Study on the mechanical properties of hydrate-bearing silty clay. Mar. Pet. Geol. 67, 72-80.

Zhang, X.H., Lu, X.B., Shi, Y.H., et al., 2015b. Centrifuge experimental study on instability of seabed stratum caused by gas hydrate dissociation. Ocean Eng. 105, $1-9$. 